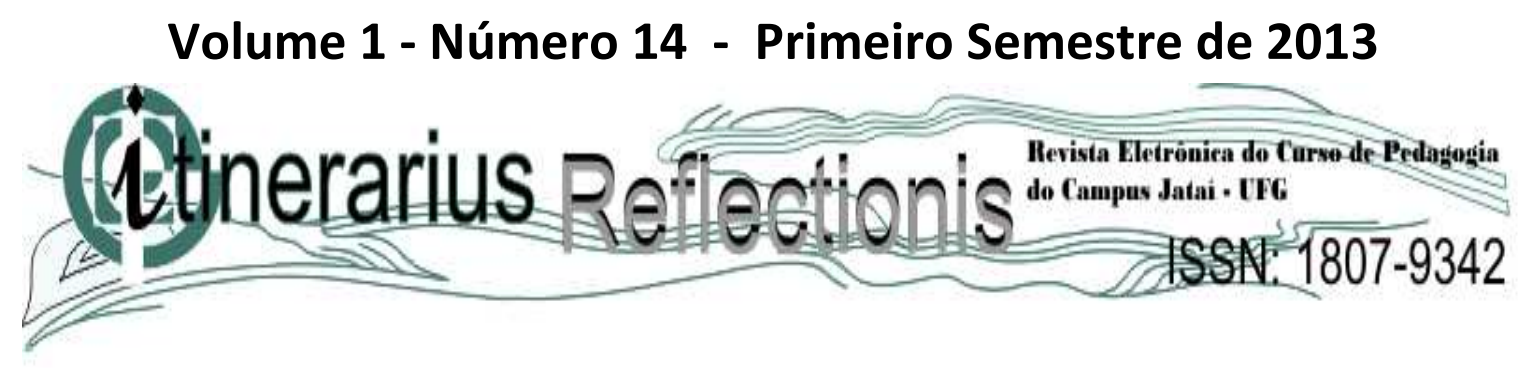

\title{
INTERVENÇÕES GRUPAIS EM PSICODRAMA: CONTRIBUIÇÕES PARA A ESCOLA DE TEMPO INTEGRAL
}

\author{
Joana D`arc Moreira Alves ${ }^{1}$ \\ Érico Douglas Vieira ${ }^{2}$
}

\begin{abstract}
A educação integral traz oportunidades complementares de formação, prometendo inovações e enriquecimento curricular, através de uma perspectiva crítico emancipadora, que possibilita aos seus sujeitos a reflexão e ação necessárias para o alcance de uma melhor qualidade de vida. O presente artigo trata-se de um estudo teórico sobre as possibilidades do trabalho com intervenções grupais nas escolas que funcionam em tempo integral. As relações interpessoais bem como as questões de gênero e da sexualidade são temas que podem ser trabalhados com metodologias grupais de intervenção. A Escola em Tempo Integral é retratada, com seus desafios e potencialidades. $\mathrm{O}$ conceito de grupos e as fases e momentos distintos pelos quais ele se constitui, levam o coordenador de grupo adequar suas intervenções como forma de potencializar a mudança. O potencial do Psicodrama para uma intervenção diferenciada e transformadora tem sido amplamente utilizado na área educacional por facilitar questões ligadas à complexidade das interações sociais e aos desafios para uma atuação educativa e formadora. As intervenções grupais contribuem para a renovação das atuações profissionais na educação, possibilitando um trabalho criativo com populações com grandes dissonâncias culturais. Também facilita a resolução de conflitos na rotina da escola, permanente desafio para educadores na difícil tarefa de intermediar alunos, professores e colegas.
\end{abstract}

Palavras-chave: Intervenções Grupais; Escola Integral; Relações interpessoais; Gênero.

\section{GROUP INTERVENTIONS IN PSYCHODRAMA: CONTRIBUTIONS TO FULL TIME SCHOOL}

\footnotetext{
${ }^{1}$ Pedagoga, Psicopedagoga, Mestranda em Educação. Professora Temporária do Curso de Pedagogia da Universidade Federal de Goiás - Campus Jataí. E-mail: psicojoanadarc@yahoo.com.br

${ }^{2}$ Psicólogo, Psicodramatista, Mestre em Psicologia, Doutorando em Psicologia. Professor Assistente do Curso de Psicologia da Universidade Federal de Goiás - Campus Jataí. E-mail: ericopsi@yahoo.com.br
} 


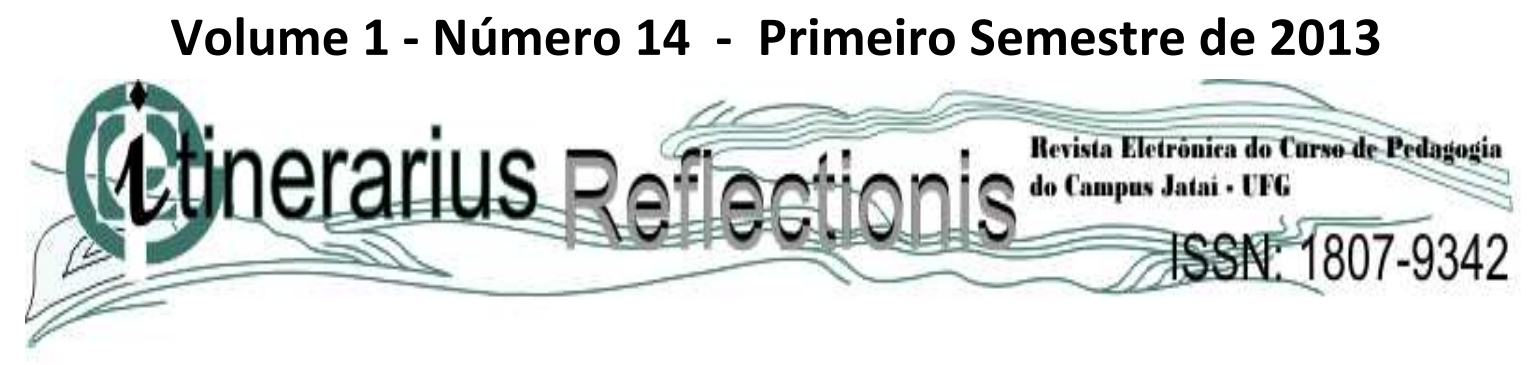

Comprehensive education brings additional training opportunities, promising innovations and curriculum enrichment, through a critical emancipatory perspective, which enables its subject the reflection and action necessary to achieve a better quality of life. This article is a theoretical study on the possibilities of working with group interventions in schools that work in a full time. The interpersonal relations as well the issues of gender and sexuality are topics that can be crafted with intervention group methodologies. The Full Time School is depicted with its challenges and potential. The concept of groups and phases and at different moments in which it constitutes, leads the group coordinator tailor their interventions in order to leverage the change. The potential of psychodrama to a differentiated and transformative intervention has been widely used in the educational area because it facilitates the complexity issues of social interactions and challenges for a educative and formative performance. The group interventions contribute to the renewal of professional performances in education, enabling a creative work with populations with large cultural discrepancies. It also facilitates the resolution of conflicts in the school routine, ongoing challenge for educators in the difficult task of intermediate students, teachers and classmates.

Keywords: Group Interventions; Comprehensive School; Interpersonal Relations; Gender.

\section{Introdução}

O ser humano é um ser eminentemente social. Desde o nascimento está inserido em grupos. O primeiro deles é a família e no decorrer da história de vida de uma pessoa, ocorre o pertencimento a inúmeros grupos sociais. Outros grupos sociais como instituições educacionais, religiosas bem como as diversas relações sociais é o terreno no qual o indivíduo constrói seus valores e sua identidade.

Dessa forma, estabelecendo relações no decorrer da vida, o indivíduo gradativamente constrói a sua maneira de colocar-se no mundo, num processo contínuo, nas trocas relacionais realizadas nos grupos nos quais circula.

O processo de desenvolvimento de um grupo pode proporcionar a seus integrantes condições de evolução e crescimento pessoal. Participar de um grupo pode significar 


\section{Volume 1 - Número 14 - Primeiro Semestre de 2013}

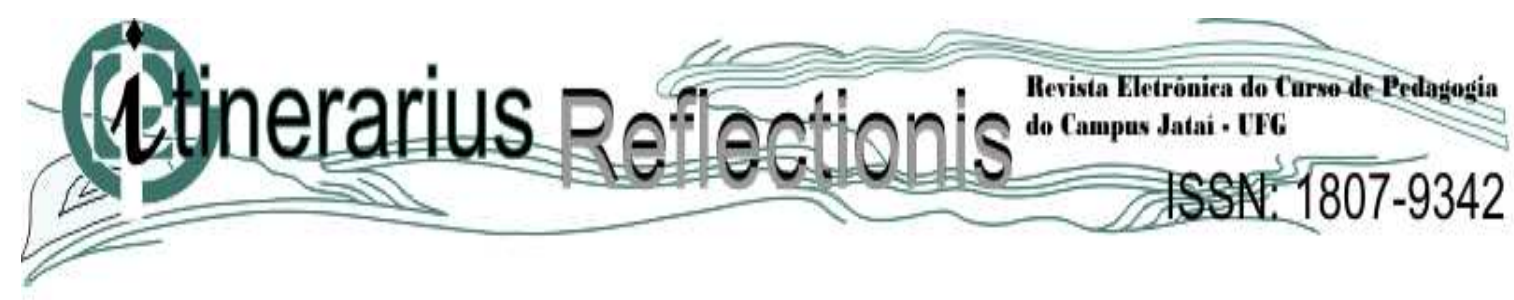

partilhar representações, crenças, informações, pontos de vista e emoções. Além disso, é a oportunidade na qual aprendemos a desempenhar diversos papéis, tais como o de filho, mãe, estudante, profissional, etc.

Nessa perspectiva, considerando-se o caráter essencialmente social do ser humano, pode-se afirmar que seu adoecimento ou a ativação de seu potencial ocorre na dependência das suas relações sociais e grupos em que participa. O ser humano está intimamente ligado ao seu universo social, influenciando e sendo influenciado por ele.

Neste sentido, a importância das intervenções em grupo fica nítida, o trabalho em grupo conduzindo por coordenadores especializados pode maximizar as potencialidades terapêuticas presentes num grupo. Dessa forma, os grupos tornam-se espaços privilegiados de crescimento e desenvolvimento pessoal. Os fatores terapêuticos são os mecanismos responsáveis pelas mudanças em um grupo e, se forem conhecidos e manejados pelo coordenador, aumentam a eficiência de uma intervenção grupal (YALOM, 2006).

É nessa perspectiva que pensamos o trabalho com grupos na escola integral. Devido aos conflitos recorrentes na rotina diária da escola e da sala de aula, uma vez que os alunos lá permanecem por muito tempo, faz-se necessário o uso de metodologias eficazes para transformar a convivência entre aluno, professor e colegas em relações mais respeitosas e afetivas, capazes assim de favorecer uma melhor aprendizagem.

Além destes conflitos os trabalhos em grupos com o tema da diversidade, gênero e educação sexual podem ser muito produtivos, proporcionando a oportunidade de a comunidade escolar adquirir diversos conhecimentos indispensáveis ao aprimoramento humano.

Com foco socioeducacional e não clínico-terapêutico, o trabalho com grupos, fundamentado na metodologia do Psicodrama, pode contribuir para explicitar diferentes questões que se colocam no dia a dia escolar, como por exemplo, as de exclusão e rejeição. Isto pode auxiliar na construção da identidade pessoal e do grupo, promovendo a busca e o desenvolvimento da cidadania e da ética, ainda tão pouco praticadas no 


\section{Volume 1 - Número 14 - Primeiro Semestre de 2013}

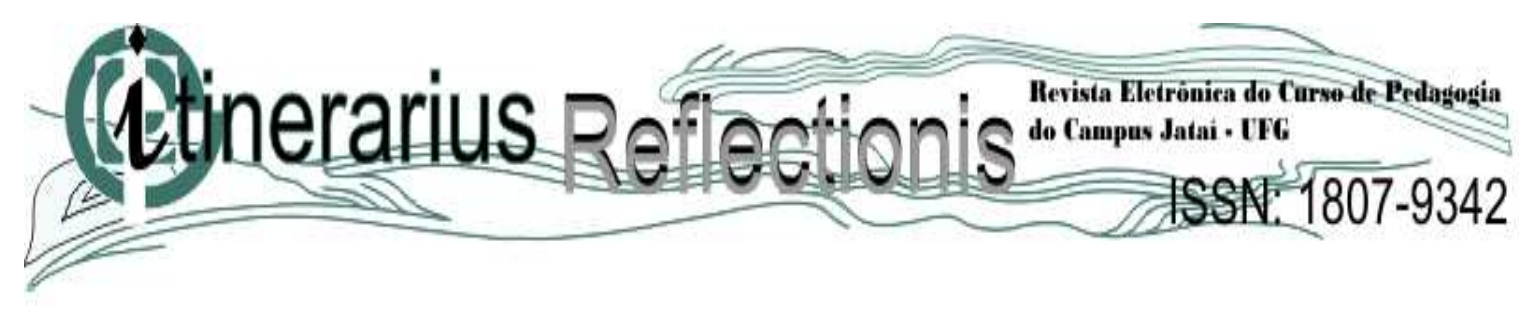

cotidiano. Cidadania, diversidade e ética também fazem parte do programa da educação integral.

Algumas situações adversas podem ser identificadas no cotidiano das escolas integrais: falta de habilidades relacionais de professores e funcionários para com alunos; problemas com infraestrutura que compromete a saúde e o aprendizado dos alunos; salas com grande quantidade de alunos; crianças com necessidades especiais e dificuldades de aprendizagem sem atendimento adequado e o que mais nos interessa, por ser o foco do presente trabalho, os estereótipos de gênero e os preconceitos veiculados pelos professores e funcionários no trato com as crianças.

Portanto, pretende-se suscitar reflexões sobre possibilidades de intervenções em grupo com métodos de ação, calcados no método do Psicodrama, fomentando um diálogo empático para a exploração livre de temas como as relações interpessoais, as questões de gênero e da sexualidade.

Assim, poderia ser fornecida uma metodologia adequada para professores e funcionários da escola integral, instrumentando-os para intervenções eficazes e, ao mesmo tempo, éticas com os alunos.

\section{Reflexões sobre a Escola em Tempo Integral no Brasil}

Pensando em termos de uma política pública de educação, a concepção de educação integral conforme proposta nos documentos governamentais existentes, traz oportunidades complementares de formação, prometendo inovações e enriquecimento curricular, através de uma perspectiva crítico emancipadora, que possibilita aos seus sujeitos refletir e agir rumo a melhorias significativas da qualidade de vida.

Nesta perspectiva crítico emancipadora que nos permite refletir sobre a função social da escola, Bourdieu e Passeronapud, citado por Almeida (2005) ressaltam:

Ao possibilitar às classes subalternas a apropriação do saber sistemático, revelando-lhes, por essa mediação, as relações de poder em que se estrutura a sociedade, a educação lhes permite também a compreensão do processo social global, uma vez que este saber está genética e contraditoriamente vinculado à situação social, por mais que, 


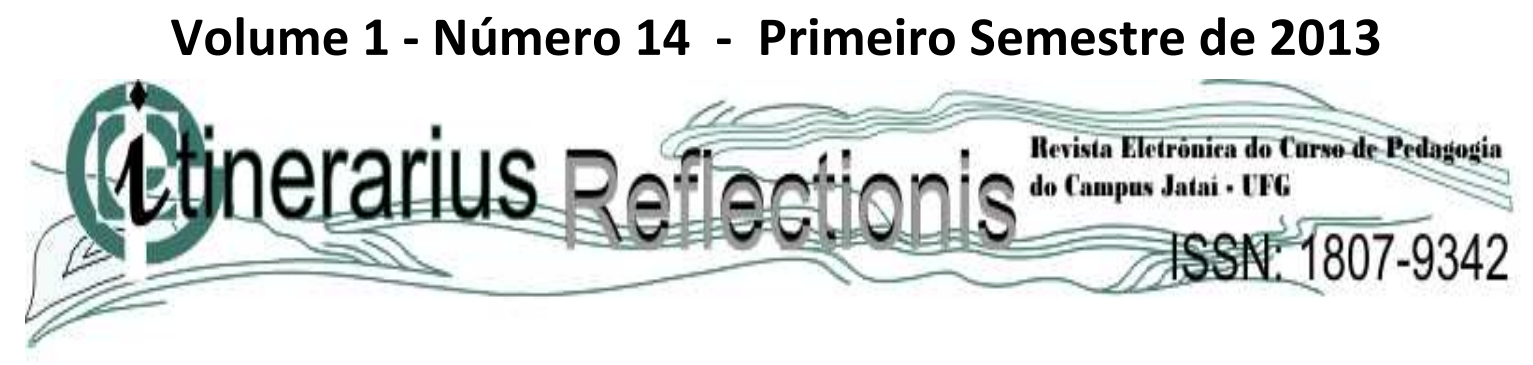

ideologicamente, se tente camuflar esta vinculação. O saber acaba levando ao questionamento das relações sociais, mediante um processo de conscientização do real significado dessas relações enquanto relações de poder, revelando inclusive a condição de contraditoriedade que as permeia. (p.151)

Como conceito para a educação integral, após a imersão de estudos sobre o tema, adotamos uma definição que, além de contemplar de forma geral as teorias existentes, traz uma ampliação no sentido de considerar também os aspectos da vida psicológica do sujeito.

Assim, educação integral trata-se de uma modalidade de ensino-aprendizagem que vê o sujeito em suas múltiplas dimensões, valorizando não apenas aspectos cognitivos, como também a compreensão de um sujeito que é corpo, tem afetos e está inserido num contexto de relações.

Os especialistas concordam que implantar a educação integral no país exige mudanças estruturais, assim como mudanças de posturas. $\mathrm{O}$ sujeito precisa ser compreendido de forma a considerar seus aspectos biopsicossociais. Acrescentamos ainda que o sujeito é também um ser que deseja, tendo não somente necessidades básicas, mas ainda demandas simbólicas, rumo à satisfação de seus desejos, ou necessidades psicológicas superiores.

A discussão sobre educação integral não é nova no cenário brasileiro. Paro (1998, p. 189) enfatiza que as reflexões tem início na década de 1920, observando que "ainda que não necessariamente ligada ao regime de período integral, mas já apontando para algumas necessidades a serem supridas pela educação". Neste período, seriam, então, gestados os primeiros elementos que, na década de 1950, passariam a constituir/esboçar como proposta de educação em tempo integral.

Dessa forma, a Escola Pública de horário integral vem sendo alvo de estudos mais sistematizados desde 2000. Ela tem origem no Manifesto dos Pioneiros da Educação Nova, escrito em 1932, tendo Anísio Teixeira como um importante ícone desse movimento. 


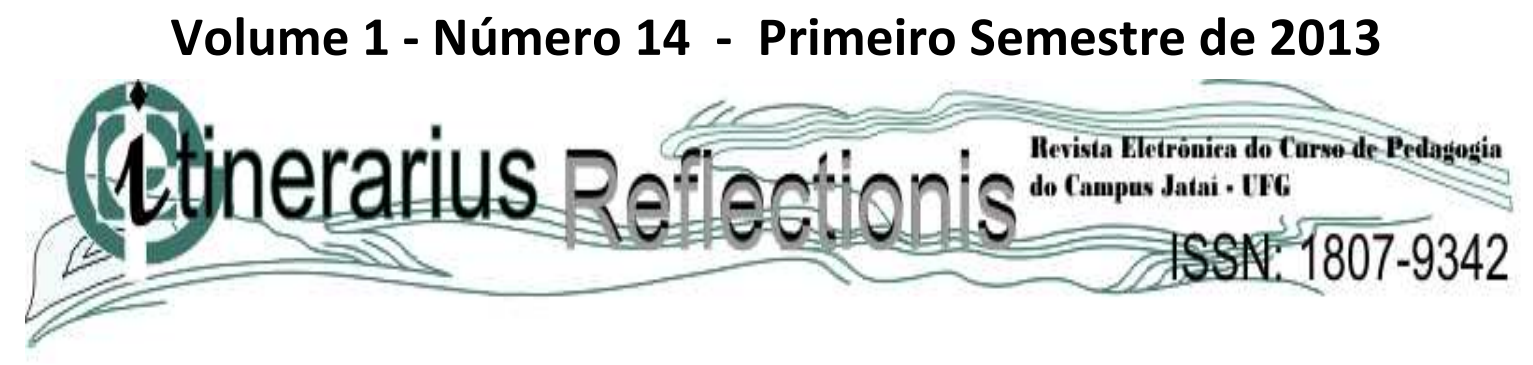

Anísio pensa numa escola nuclear - com os conhecimentos básicos e em parques escolares - com atividades mais descontraídas, diversificadas e organizadas, funcionando em dois turnos para cada criança, sendo a mesma obrigada a frequentar os dois turnos.

Neste sentido, o autor afirma:

[...] haverá escolas nucleares e parques escolares, sendo obrigada a criança frequentar regularmente as duas instalações. O sistema escolar para isso funcionará em dois turnos, para cada criança [...] no primeiro turno a criança receberá, em prédio econômico e adequado, o ensino propriamente dito; no segundo receberá, em um parque-escola aparelhado e desenvolvido, a sua educação propriamente social, a educação física, a educação musical, a educação sanitária, a assistência alimentar e o uso da leitura em bibliotecas infantis e juvenis (TEIXEIRA, 1997, p. 243).

A bibliografia comprova que a História da Educação faz referência à formação integral do indivíduo desde a antiguidade. Entretanto, é nos séculos XIX e XX que a concepção de educação integral se fortalece e na prática começa a ser realmente efetiva, mesmo que de forma bastante tímida, com poucas experiências sendo realizadas.

A modernidade traz consigo diversos benefícios e privilégios, todavia, podemos identificar também alguns problemas. Assim, as novas tecnologias, o largo desenvolvimento da ciência e a ascensão da burguesia são fatos presentes tidos por muitos como indícios de progresso. De outro lado, esse mesmo crescimento propicia outras realidades, pois o capitalismo cresce e se torna mais forte, tornando possível uma acentuada diferença entre aqueles que tem os meios de produção - os mais abastados - e os que tem apenas a força de trabalho - os pobres.

Neste sentido Aranha (1996, p. 138), afirma que "para enfrentar essas dificuldades, o proletariado surge como a classe revolucionária que opõe aos interesses burgueses suas próprias reivindicações". As próprias contradições do modo de produção capitalista e suas inúmeras consequências apontam brechas para que o povo - maioria 


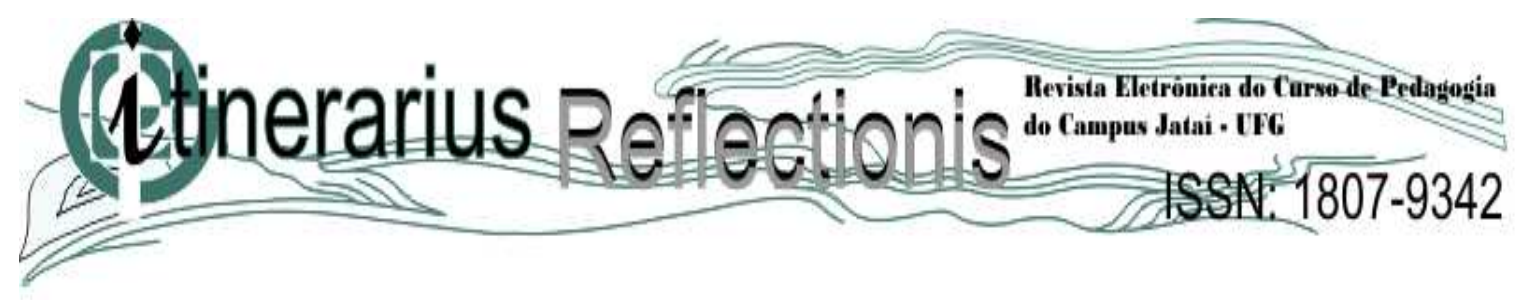

oprimida - possa se mobilizar, buscando soluções menos desumanas para diferentes problemas existentes.

Os enfrentamentos advindos dessa conjuntura tornam-se cada vez mais presentes, tendo em vista que o capitalismo se fortalece ainda mais no século XX. A burguesia busca suas conquistas, o proletariado se mostra, lutando por direitos, a filosofia e a política combatem o poder vigente, cada um com seus próprios interesses e a educação que não é isolada do contexto histórico-social - também se movimenta. A escola como instituição faz parte desse sistema social e é natural que ela também seja impactada, sofrendo resvalos dessa realidade.

O século XX ainda é um período em que surgem diversas teorias educacionais. De um lado estão aquelas que objetivam manter e aperfeiçoar o poder político vigente. Também existem outras teorias, aquelas que trabalham no sentido de transformar a realidade, superando este sistema.

Neste contexto é que a educação integral tem suas origens, de forma tímida, lenta, com algumas experiências teórico-práticas. A educação integral insere-se nessa crítica às mazelas do capitalismo, tentando trazer transformações para os sujeitos envolvidos através do fornecimento de ferramentas educativas emancipadoras.

Como foi dito anteriormente, a discussão sobre Educação Integral no Brasil intensificou-se a partir das ideias de Anísio Teixeira, educador brasileiro que focalizou este assunto em meados do século passado. Com a Lei de Diretrizes e Bases da Educação Nacional LDBN/1996, a Educação Integral é legalizada, apontando no seu texto uma gradativa ampliação da jornada escolar rumo ao regime de tempo integral.

Assim determina a Lei 9.394 (LDB, 1996) em seu Artigo 34, Parágrafo Segundo:

Artigo 34. A jornada escolar no ensino fundamental incluirá pelo menos quatro horas de trabalho efetivo em sala de aula, sendo progressivamente ampliado o período de permanência na escola. [...] $\mathbf{2}^{\mathbf{o}}$. O ensino fundamental será ministrado progressivamente em tempo integral, a critério dos sistemas de ensino. 


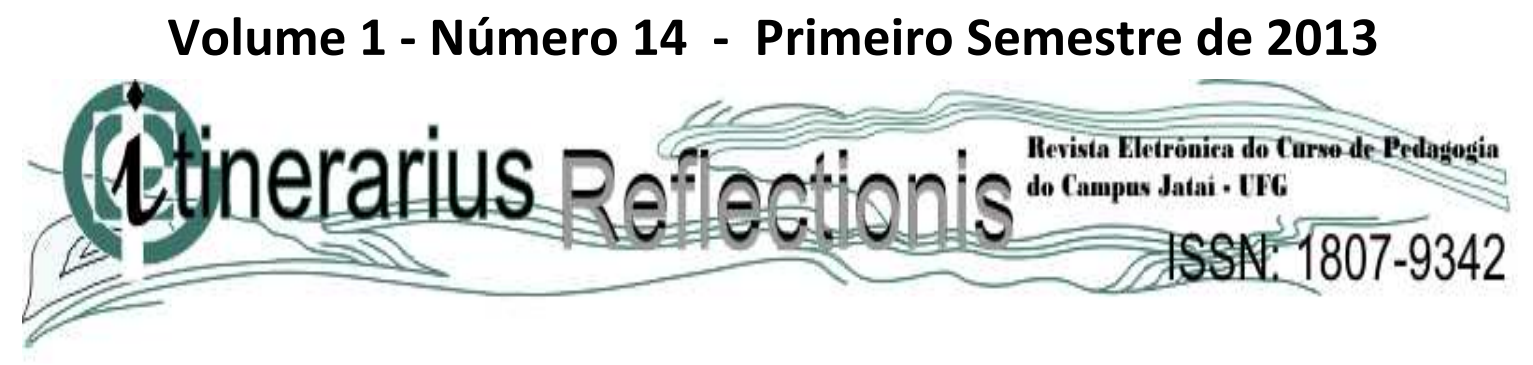

Ainda conforme a LDB, o tempo integral é entendido como as matrículas escolares em turno de duração igual ou superior a sete horas diárias. As experiências pioneiras citadas por Paro (1998) têm como foco as camadas populares e sua formação, o que em certa medida antecipa as questões que se farão presentes nas décadas seguintes, quando se "procurava atribuir à escola o papel de contribuir para a solução de problemas sociais relacionados com a condição de pobreza da população" (PARO, 1998, p. 192).

O recente Plano Nacional de Educação (PNE) de 2011, assim como o de 2001, também continua objetivando a ampliação gradativa da jornada escolar, defendendo inclusive a participação das comunidades externas a escola no ato de gerir as escolas.

\section{Intervenções grupais psicodramáticas na Escola de Tempo Integral}

Algumas diretrizes, mesmo que de forma gerais, são importantes para o trabalho eficiente com grupos, seja dentro ou fora da comunidade escolar.

Zimerman (2000) esclarece que um grupo só pode ser reconhecido como tal se estiver de acordo com as seguintes características básicas: um grupo não é somente um conjunto de pessoas juntas, mas se constitui a cada encontro como uma identidade nova, possuindo suas próprias e especificas leis, assim como seus mecanismos; um objetivo comum é o eixo norteador do grupo, em torno do qual estão todos os integrantes; é preciso ter cuidado com o tamanho do grupo, de forma que os princípios das diversas formas de comunicação não seja prejudicada; deve haver objetivos definidos, estabilidade de espaço, de tempo, além de regras para normatizar a atividade em grupo.

O Psicodrama, método criado por Jacob Levy Moreno, transcende os métodos individuais e verbais ao propor a ação no grupo. Através do uso de técnicas de ação, são desvelados os sentidos e abertas novas perspectivas antes latentes (MORENO,1975). Há o princípio da espontaneidade, no qual os participantes são estimulados a interagirem livremente e o princípio da interação terapêutica, no qual cada membro torna-se agente terapêutico do outro. 


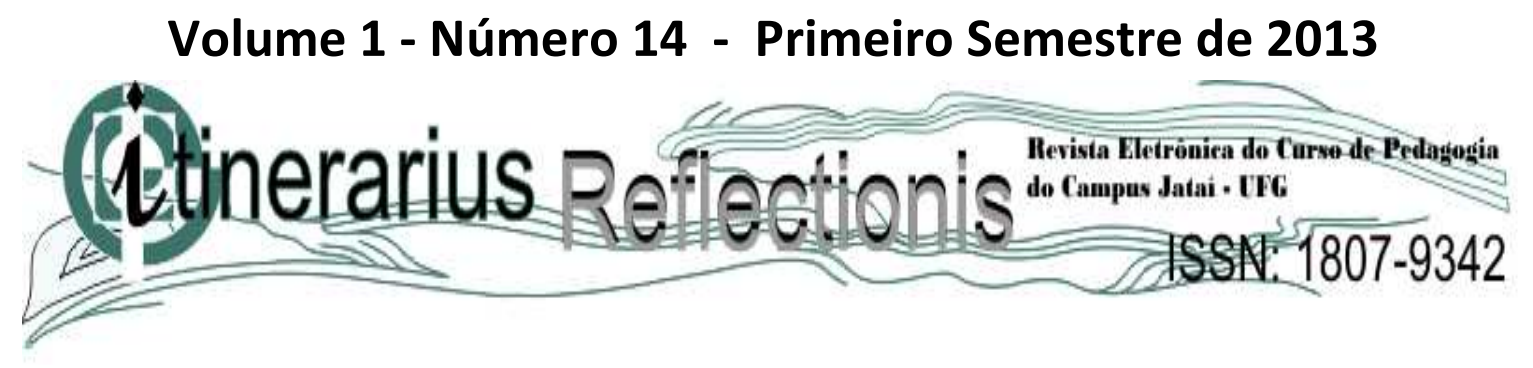

Sendo assim, a liberdade para a ação e a expressão suscita o desenvolvimento de respostas criativas e o potencial terapêutico é distribuído entre os membros do grupo, ou seja, as intervenções eficazes não são feitas somente pelo coordenador (KNOBEL, 1996).

O Psicodrama lança luz sobre as fases pelas quais um grupo evolui e é sumamente importante que o coordenador saiba em que fase o grupo se encontra para que ele possa manejar o grupo adequadamente.

A primeira fase seria o momento de isolamento, no qual há poucos contatos entre os membros do grupo, devido ao clima tenso e desconfiado pelo fato de as pessoas ainda não se conhecerem. Não existe a realização de tarefas coletivas e há pouca discriminação de características individuais.

O coordenador do grupo deve centralizar a comunicação em si mesmo, respeitando o momento de fechamento do grupo. Deve, ainda, fazer o contrato do grupo, descrevendo e reafirmando os objetivos das atividades grupais. Aos poucos, o coordenador pode promover breves contatos entre os membros (KNOBEL, 1996).

De acordo com Yalom (2006), o coordenador do grupo deve estar atento à coesão grupal, que proporciona a segurança que permite a expressão de sentimentos e a disponibilidade em se arriscar a experimentar novos comportamentos pessoais. A partir das ideias de Yalom (2006), se o grupo está coeso, outros fatores terapêuticos podem entrar em ação.

O segundo momento do grupo seria a diferenciação horizontal, no qual há um início de organização e um início de maiores trocas relacionais entre as pessoas. Os membros do grupo se mostram uns para os outros e tentam examinar conhecer cada um. Pode haver o prazer em se exibir e em descobrir o outro.

O risco é a vontade de sair do grupo, caso não se tenha sucesso ao se mostrar, que pode ser sentido como rejeição. O coordenador do grupo deve propor atividades que proporcionem muitos contatos entre os membros, bem como valorizar as diferenças e as singularidades.

Um terceiro e último momento seria o da diferenciação vertical no qual há o aparecimento de lideranças e subgrupos com objetivos em comum. O grupo oscila entre a 


\section{Volume 1 - Número 14 - Primeiro Semestre de 2013}

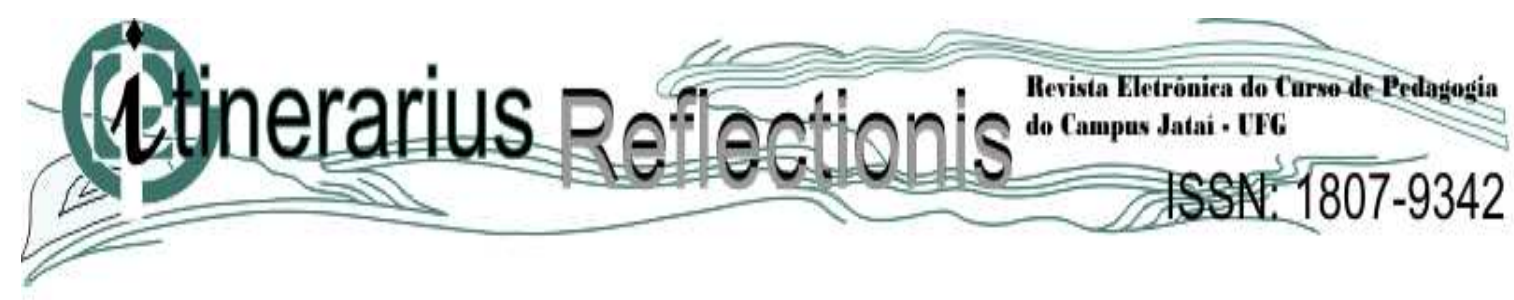

competição e a cooperação, podendo haver inveja e disputa de espaço. Somente nessa fase o grupo pode alcançar seus objetivos.

O coordenador deve auxiliar no aparecimento de lideranças, focalizando os objetivos em comum propondo ações que coloquem o grupo rumo à realização da tarefa. O coordenador deve, ainda, apontar as ações que possam desviar o grupo do seu objetivo em comum (KNOBEL, 1996).

O potencial do Psicodrama para uma intervenção diferenciada e transformadora tem sido amplamente utilizado na área educacional por facilitar questões ligadas à complexidade das interações sociais e aos desafios para uma atuação educativa e formadora.

Importante faz-se frisar que cada grupo desenvolve sua cultura de acordo com seus integrantes, porém é o coordenador, líder ou terapeuta que estabelece o rumo a ser tomado, identificando o que é de interesse nos assuntos relacionados ao grupo, primando pelo fortalecimento da experiência emocional no relacionamento em grupo.

Espontaneidade, criatividade, tolerância e flexibilidade são alguns requisitos importantes para o psicoterapeuta e para o coordenador de um grupo. Considerar a dinâmica de diversos tipos de grupo e oferecer métodos para intervir em conflitos é um foco importante, sob o qual esse coordenador precisa estar sempre atento.

No processo de interação dentro do grupo aparecem novas forças, que embora originadas no indivíduo, somente ocorrem devido à interação com os outros membros (MAILHIOT, 1991).

O grupo pode passar por momentos diferenciados. Mesmo em um grupo onde há um bom desempenho, com relacionamentos integrados e boas relações de respeito e confiança, podem ocorrer situações de menores rendimentos.

Nesse momento o terapeuta ou coordenador precisa buscar e empregar estratégias para recuperara produtividade já alcançada outrora ou focar em ações que tornem o grupo produtivo.

Boris (2007), apresenta a importância do atendimento em grupo: 


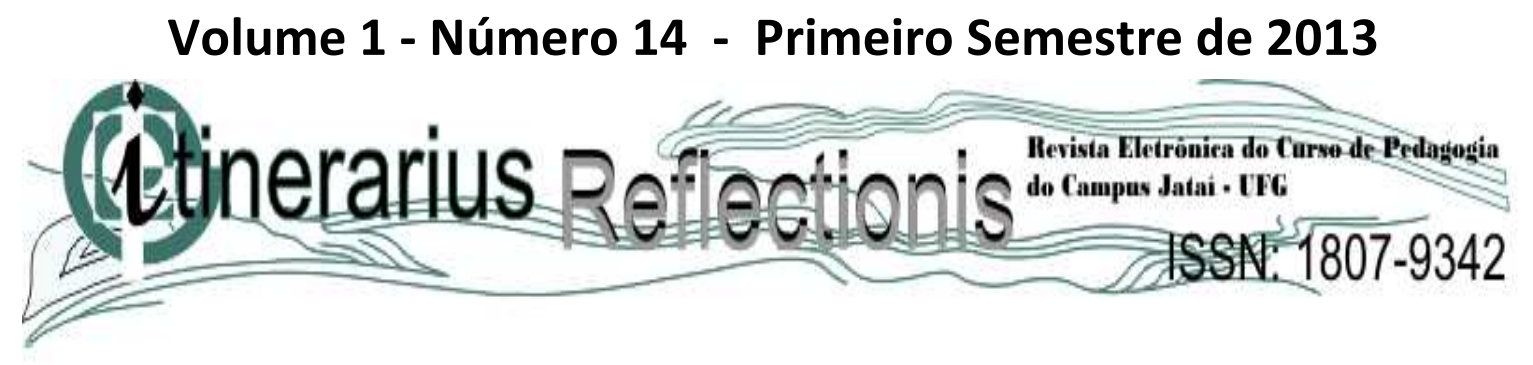

Sem dúvida, o grupo como comunidades de aprendizagem cooperativa não são uma panacéia para todos os males.Entretanto, são uma forma efetiva de atuação para psicólogos educadores,psicoterapeutas e outros profissionais comprometidos com a transformação social, a fim de facilitar a essas comunidades humanas, os grupos, a conscientização de sua alienação e vitimação à manipulação consumista e às relações de dominação. [...] $\mathrm{O}$ trabalho grupal exige toda nossa atenção, afeto, dedicação, estudo e conhecimento acerca dos seres humanos e dos fenômenos característicos aos grupos e à sua realidade sócio-histórica concreta (p.183).

As intervenções grupais na escola de tempo integral podem contribuir para a saúde, para a qualidade de vida dos alunos e demais membros da comunidade escolar. Através do trabalho com grupos, poderemos proporcionar oportunidade de os alunos aprenderem e crescerem fazendo, sorrindo, chorando, se movimentando e refletindo, representando nossas inúmeras possibilidades criativas.

Os grupos sócio-educativos, denominado assim por se diferenciar de uma psicoterapia de grupo, proporcionam um processo de crescimento prazeroso, no qual a alegria de compartilhar sentidos rompe o isolamento individualista. $\mathrm{O}$ trabalho em grupo com alunos da escola integral pode atenuar as ansiedades dos alunos, contribuindo para melhores relacionamentos interpessoais e melhorando a capacidade de aprendizagem.

Uma dos temas que podem receber a atenção das intervenções em grupo são as questões de gênero e da sexualidade que ainda geram medos, tabus e preconceitos na sociedade de forma geral e no meio escolar, em especial.

Nos últimos anos a diversidade sexual, o enfrentamento do sexismo e a homofobia, vêm sendo alvo de discussões crescentes, o que proporciona a possibilidade de desconstruir formas de aprender/ensinar e construir caminhos metodológicos para que outras práticas sejam realizadas no cotidiano da escola.

A sala de aula, a escola e em particular a escola de tempo integral, por passar mais tempo com a criança sob sua responsabilidade, pode ser um lugar privilegiado para se 


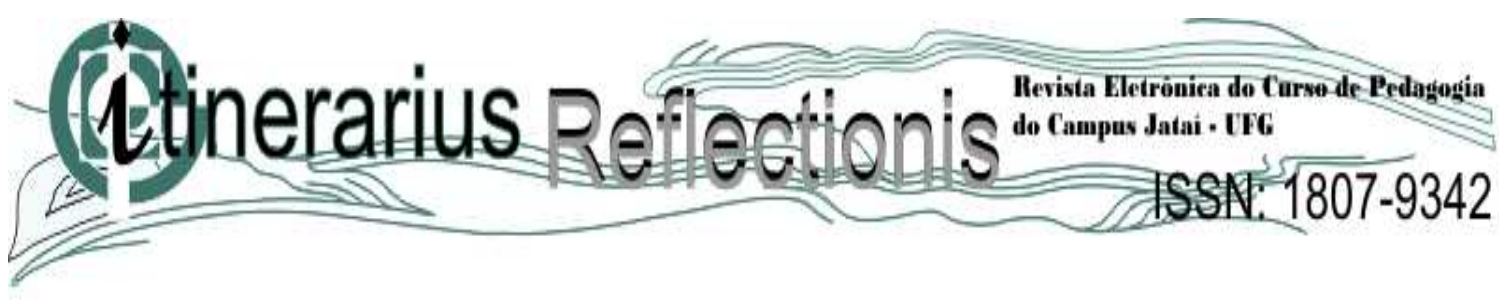

promover a cultura de reconhecimento da pluralidade das identidades e dos comportamentos relativos às diferenças.

Percebe-se a importância de se discutir a educação escolar a partir de uma perspectiva crítica e problematizadora, questionar relações de poder, hierarquias sociais opressivas e processos de exclusão, que as concepções curriculares e as rotinas escolares, presentes no interior da escola, tendem a preservar (SILVA, 2001).

A escola de tempo integral surge com a proposta de resgatar muitas reflexões já existentes na educação para os que defendem a ampliação da jornada escolar. A reinvenção da prática educativa, ganha na proposta da escola integral um canal a mais de reflexão e ação rumo a uma realidade dinâmica, viva, de interação entre aprendizagens diversas, abandonando o isolamento teórico e, consequentemente, prático a que estamos acostumados experienciar nos últimos anos.

Os Parâmetros Curriculares Nacionais, de acordo com a lei de Diretrizes e Bases, LDB/96 propõem orientações gerais sobre o currículo básico. Na tentativa de compor um conjunto articulado e aberto a novos temas e ainda visando uma educação voltada para a construção da cidadania, foram criados os Temas Transversais. São eles: Ética, Saúde, Meio Ambiente, Pluralidade Cultural e Orientação Sexual.

Dessa forma, acredita-se que a escola de tempo integral tem, até por uma questão legal, a obrigação de trabalhar um projeto contemplando a reflexão e o desenvolvimento de ações e atitudes que permeiem a questão de gênero e sexualidade, tendo em vista a diversidade, a pluralidade cultural e o aluno concreto existente na escola.

Os grupos sócio-educativos na proposta do Psicodrama, facilitam as interações espontâneas entre os membros, possibilitando a construção de novos sentidos e a experimentação de novos comportamentos.

\section{Considerações Finais}

Numa sociedade caracterizada - ao menos no plano teórico - pela diversidade, pelo pluralismo cultural e pela inclusão, faz-se imprescindível pensar não somente numa 


\section{Volume 1 - Número 14 - Primeiro Semestre de 2013}

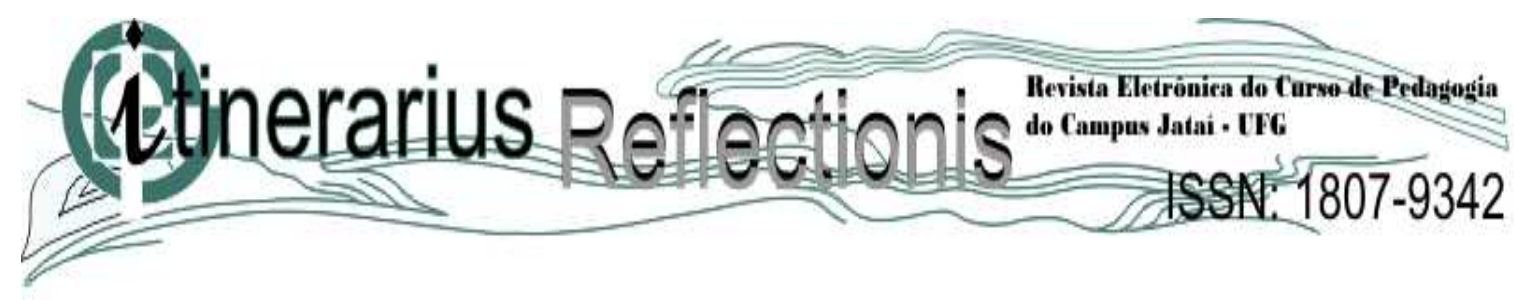

escola que funcione em tempo integral, mas, sobretudo numa educação de tempo integral, que prime por integrar em seu currículo e em suas práticas pedagógicas, temas fundamentais para o desenvolvimento de seus alunos, como os relacionamentos interpessoais e as questões do gênero e de sexualidade.

O efetivo compromisso com essa reflexão precisa tornar-se realidade experienciada, vivida e respeitada na escola, especialmente na que funciona em tempo integral, pois esta tem um período mais extenso com os alunos sob sua orientação, o que, consequentemente, aumenta sua responsabilidade.

Assim, a educação - incluindo as relações de gênero e sexualidade - de negros, homossexuais, pobres, deficientes físicos, alunos com limitações intelectuais presentes nos espaços dessa escola integral, precisa se movimentar no sentido de que essas minorias, que juntas se tornam a maioria, sejam vistas, respeitadas, participando ativamente do processo de aquisição do conhecimento em sua totalidade e considerando sua característica multifacetada.

Entendemos que, dessa forma, essa escola não somente deve preparar para a cidadania, mas desde já, vivenciar a cidadania, pois essa é a melhor maneira de os alunos tornarem-se cidadãos. Este é, a nosso ver, o maior desafio da educação atual e da educação na escola de tempo integral, em particular.

É nesta perspectiva que pensamos o Psicodrama com a modalidade dos grupos sócio-educativos, uma vez que este tem como objetivo fazer com que o indivíduo possa resgatar a liberdade de poder utilizar suas próprias capacidades para existir, reaprendendo a utilizar a sua liberdade de forma responsável, para ser o que ele é.

Neste sentido o Psicodrama promove uma relação terapêutica que privilegia o encontro existencial $\mathrm{Eu}-\mathrm{Tu}$, recriando e facilitando o encontro na vida, o que tornaria as vivências escolares mais carregadas de sentido, influenciando diretamente a construção de relacionamentos saudáveis e de uma aprendizagem mais eficaz.

Moreno propõe um trabalho voltado à ação, preferencialmente em grupos (MORENO, 1975). Parte da visão de que uma pessoa constrói-se através de uma multiplicidade de papéis, de um processo que é coletivo e, ao mesmo tempo, composto 


\section{Volume 1 - Número 14 - Primeiro Semestre de 2013}

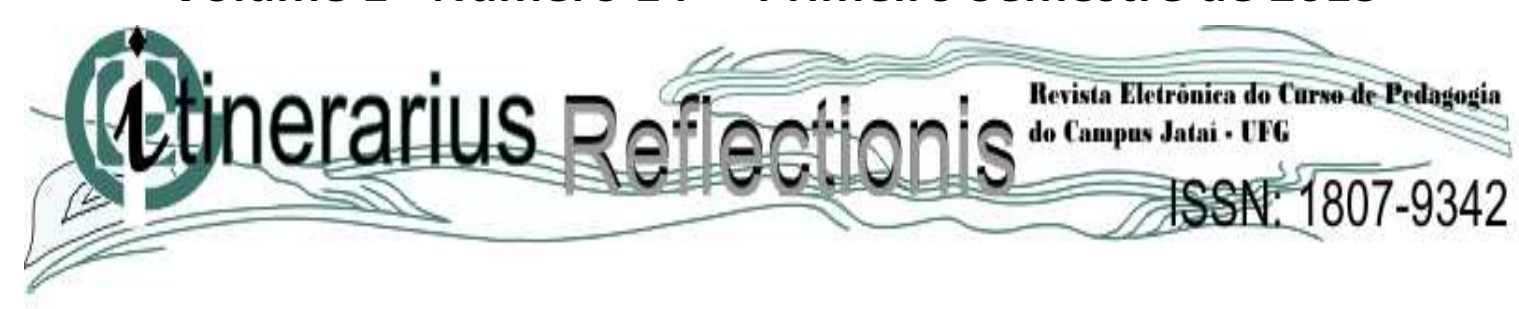

por singularizações. É nessa perspectiva que caminha a nossa reflexão sobre o processo de intervenção grupal na escola integral, instituição onde os alunos passam um terço do dia.

Esperamos que este trabalho possa trazer reflexões sobre as intervenções grupais na escola integral como uma prática possível e enriquecedora para a comunidade escolar, considerando os desafios que a mesma enfrenta num momento de transformações rápidas, onde a construção de gênero e sexualidade, com certeza se fazem presentes, agora já não só no plano teórico, mas com manifestações reais no cotidiano da escola.

Assim, as intervenções grupais contribuem para a renovação das atuações profissionais na educação, possibilitando um trabalho criativo com populações com grandes dissonâncias culturais. Também facilita a resolução de conflitos na rotina da escola, permanente desafio para educadores na difícil tarefa de intermediar alunos, professores e colegas.

\section{Referências}

ALMEIDA, Lenildes Ribeiro Silva. Pierre Bordieu: a transformação social no contexto de "A reprodução". INTER-AÇÃO. Revista da Faculdade de Educação, Editora da UFG, Goiânia, v. 30, n. 1, p. 139-155, 2005.

ARANHA, M. L. A Filosofia da educação. $2^{a}$ ed. São Paulo: Moderna, 1996.

GUARÁ, Maria Rosa. É imprescindível educar integralmente. Cadernos Cenpec: Educação Integral, n.2, São Paulo: Cenpec, 2006.

KNOBEL, Ana Maria. Estratégias de direção grupal. Revista Brasileira de Psicodrama, v.4, n.1, 1996.

KOSSOY, Boris. Os Tempos da Fotografia: O Efêmero e o Perpétuo. Cotia, S.P: Ateliê Editorial, 2007.

MAILHIOT, Gerald B. Dinâmica e gênese dos grupos: atualidade das descobertas de Kurt Lewin. São Paulo: Duas Cidades, 1991. $7^{\text {a }}$. 


\section{Volume 1 - Número 14 - Primeiro Semestre de 2013}

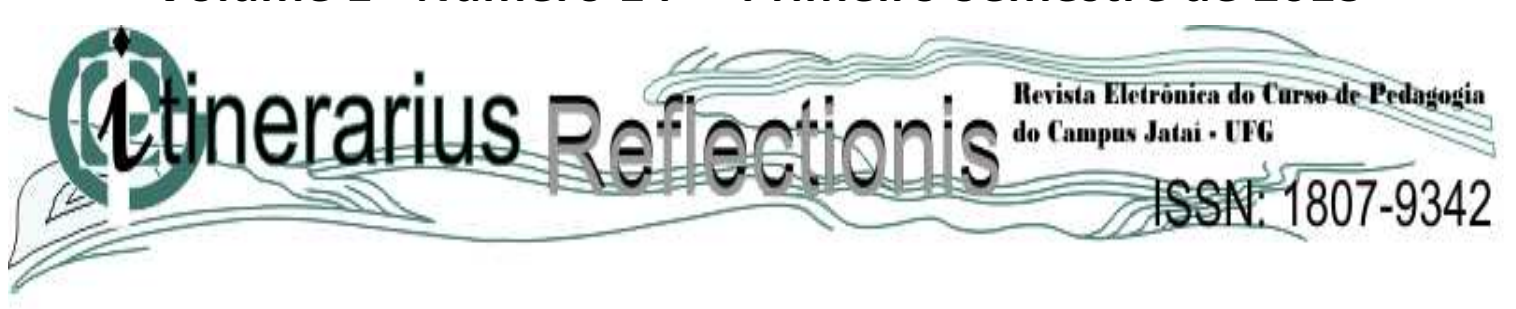

MOLL, Jaqueline. Educação de Jovens e Adultos. Projetos Práticos e Pedagógicos. Porto Alegre: Mediação, 2004.

MORENO, Jacob Levy.Psicodrama. São Paulo: Cultrix, 1975.

NERY, Maria da Penha.Vínculo e afetividade: caminhos das relações humanas. São Paulo:Ágora, 2003.

OSÓRIO, Luiz Carlos. Grupos: teorias epráticas, acessando a era da grupalidade. Porto Alegre: Artes Médicas Sul, 2000.

PARO, Vitor; et al. Escola de tempo integral: desafio para o ensino público. São Paulo: Cortez/ Autores Associados, 1988.

RESENDE, Antônio Muniz de. Concepção Fenomenológica da Educação. São Paulo: Cortez, 1990.

ROMAÑA, Maria Alícia. Psicodrama Pedagógico . São Paulo: Ágora, 1986.

SILVA, Maria Júlia Paes da. Comunicação tem Remédio. São Paulo: Editora Gente, 2001 .

TEIXEIRA, Anísio. Administração pública brasileira e a educação. Revista Brasileira de Estudos Pedagógicos. Rio de Janeiro, v.25, n.63, 1956. p.3-23

YALOM, Irving. Psicoterapia de grupo: teoria e prática. Porto Alegre: Editora Artmed, 2006.

ZIMERMAN, David. Fundamentos Básicos das Grupoterapias. Porto Alegre: Editora Artmed, 2000.

WEIL, Pierre (org.). Dinâmica de grupo e desenvolvimento em relações humanas. Belo Horizonte: Itatiaia, 2002. 